spondylitis. ${ }^{5}$ Hajjaj-Hassiouni et al described two cases of ankylosing spondylitis with the nephrotic syndrome where amyloid was demonstrated in a rectal biopsy specimen, ${ }^{6}$ Geffriaud et al followed up six patients with systemic AA amyloidosis and ankylosing spondylitis. ${ }^{5}$ Renal failure eventually occurred in all six between three and 31 years (with a mean of 19 years) after the onset of rheumatological symptoms.

Amyloidosis is a well recognised cause of the nephrotic syndrome, and end stage renal failure is the cause of death in $13-68 \%$ of cases of systemic AA amyloidosis. ${ }^{157-10}$ AA amyloidosis may present many years after the onset of the underlying inflammatory disorder, which may appear to be clinically inactive at the time of presentation. ${ }^{9}$ In a recently published series from the Mayo Clinic the mean time elapsed between onset of symptoms attributable to inflammatory disease and a tissue diagnosis of AA amyloid was 18.3 years. ${ }^{1}$

Our patient developed a nephrotic syndrome 44 years after the onset of symptoms attributable to ankylosing spondylitis. At the time of writing he retains adequate renal function. Progression of his renal disease has thus been slower than in the six patients in Geffriaud's series. ${ }^{5}$

Immunostaining of amyloid with specific antisera to the components of amyloid fibrils is not routinely performed in many pathology departments including, until now, our own. In the authors' opinion this case shows that immunostaining of amyloid should be routinely adopted to avoid overlooking occult or apparently quiescent underlying disease.

We thank Professor Robert A Kyle for reading the manuscript and giving us the benefit of his long experience in the field of amyloidosis.

1 Gertz MA, Kyle RA. Secondary systemic amyloidosis: response and survival in 64 patients. Medicine 1991;70: 246-2.

2 Wright JR, Calkins E, Humphrey RL. Potassium permanganate reaction in amyloidosis. Lab Invest 1977;36: 274-81.

3 Noël LH, Droz D, Ganeval D. Immunohistochemical characterisation of renal amyloidosis. Am $\mathcal{f}$ Clin Pathol 1987;87:756-61.

4 Bayles TB. Rheumatoid arthritis and rheumatic heart disease in autopsied cases. Am $\mathcal{F}$ Med Sci 1943;205: 42-8.

5 Geffriaud C, Noël LH, Blanche P, et al. Spondylarthritis ankylosante avec amylose de type AA: six observations.

Press Med 1988;17:2344-7.
6 Hajjaj-Hassiouni N, Laghrissi S, Khalil A, et al. Spondylarthrite ankylosante et amylose: deux observations. Rev Rheum 1988;49:687-91.

7 Brandt K, Cathcart E, Cohen AS. A clinical analysis of the course and prognosis of forty-two patients with amyloidosis. Am ₹ Med 1968;44:955-9.

8 Kyle RA, Bayrd ED. Amyloidosis: a review of 236 cases. Medicine 1975;54:271-99.

9 Wright JR, Calkins E. Clinical pathological differentiation of common amyloid syndromes. Medicine 1981;60: 429-48.

10 Triger DR, Jokes AM. Renal amyloidosis. A 14 year followup. $Q f$ Med 1973;165:15-40.

\title{
Lobular carcinoma in a mammary hamartoma
}

\author{
J Coyne, F M Hobbs, C Boggis, R Harland
}

\footnotetext{
Department of Histopathology

J Coyne

F M Hobbs

Department of

Radiology

C Boggis

Department of

Surgery

R Harland

Withington Hospital, Manchester

Correspondence to:

Dr J Coyne,

Department of

Histopathology, Withington

Hospital, Nell Lane,

Manchester M20 8LR.

24 March 1992
}

\begin{abstract}
Mammary hamartomas are uncommon breast lesions, sometimes presenting as mammographic abnormalities which require pathological clarification. Previous cases have all been benign. A unique case of mammary hamartoma containing atypical lobular hyperplasia (ALH), lobular carcinoma in situ (LCIS), and foci of microinvasive lobular carcinoma is presented. The need for adequately sampling macroscopically innocuous breast lesions is emphasised.
\end{abstract}

(F Clin Pathol 1992;45:936-937)

\section{Case report}

A 59 year old woman had a $5 \mathrm{~cm}$, well defined opacity incorporating a fatty component, which was located in the upper, inner quadrant of the left breast, detected at mammography (fig 1). A soft, round, mobile mass was palpable and this was considered to be benign clinically. A fine needle aspirate showed very few, small clusters of benign epithelial cells. Because of the patient's anxiety, an excision biopsy was performed.

\section{Pathology}

The specimen measured $6 \times 5 \times 3 \mathrm{~cm}$ and contained an ovoid well circumscribed mass measuring $3 \mathrm{~cm}$ in maximum diameter. It had a yellow and white variegated cut surface and was firm and rubbery in consistency. Microscopically, the lesion was focally surrounded by a thin layer of fibrous tissue containing occasional compressed ducts. The overall pattern consisted of individual and clustered lobular units separated by dense, hyalinised fibrous tissue which were separated by abundant fatty 


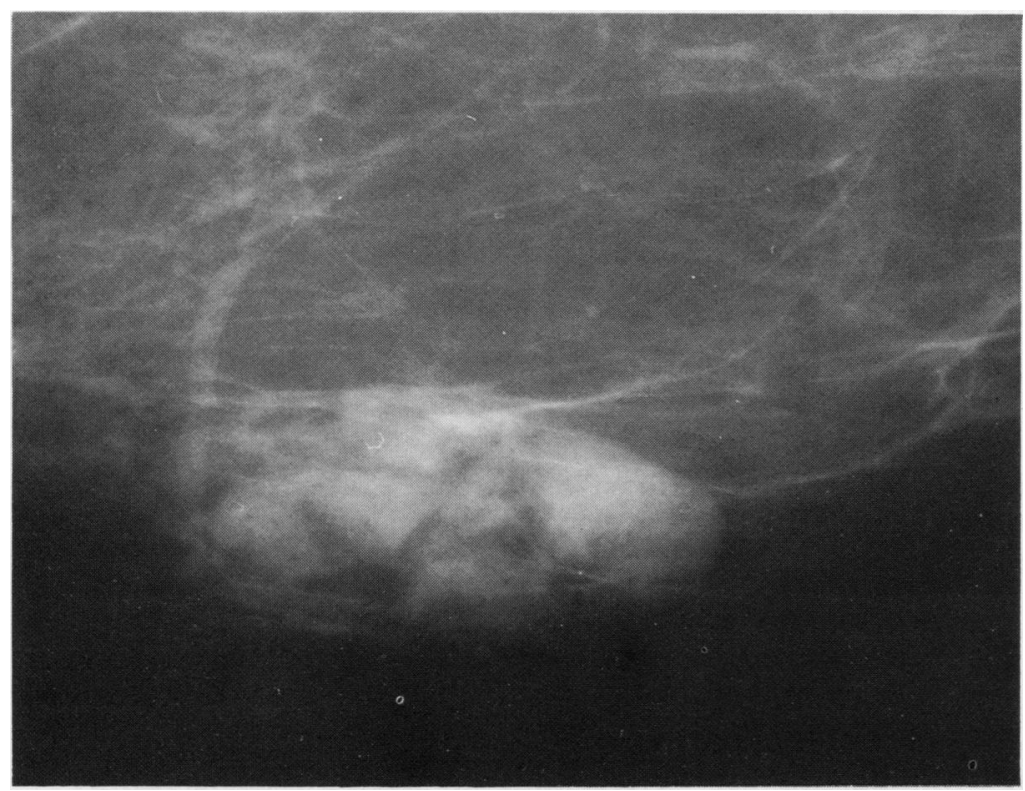

Figure 1 Circumscribed radiographic lesion with translucent areas.

tissues (fig 2). The normal, loose intralobular tissue was completely replaced by paucicellular, fibrous tissue. In those places where the fat approximated the epithelial elements, the ducts and acini retained a thin investing layer of fibrous tissue. The entire specimen was blocked, and sections from eight of the 14 lesional tissue pieces contained foci of lobular neoplasia. Throughout the eight sections 24 lobules (in six sections) showed atypical lobular hyperplasia (ALH), four ducts (in three sections) showed pagetoid spread, and four lobules (in three sections) showed lobular carcinoma in situ (LCIS). Two of the three sections showing foci of lobular carcinoma in situ displayed adjacent foci of microinvasive (less than $1 \mathrm{~mm}$ in maximum dimension) lobular carcinoma (fig 3). These two microinvasive carcinomas were present in two sections containing only one and two lobules, respectively, distended by LCIS. All foci of lobular neoplasia comprised clustered lobules in each section. A focus of atypical ductal

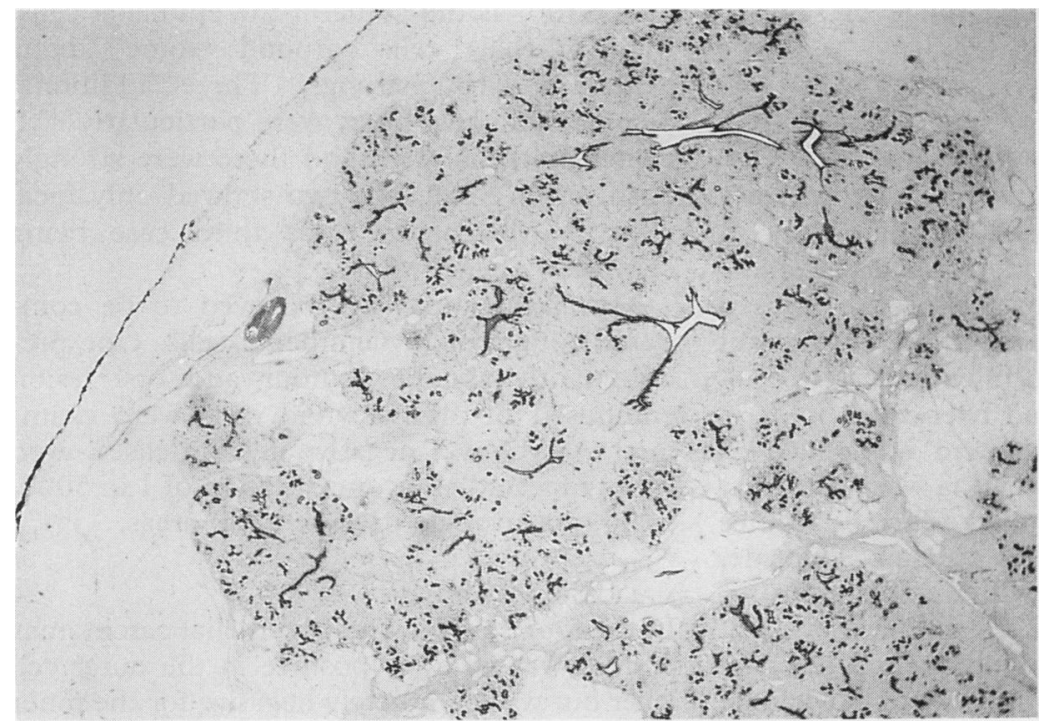

Figure 2 Lobules in dense fibrous stroma and interlobular adipose tissue. hyperplasia was present in the small amount of attached fatty breast tissue.

\section{Discussion}

Arrigoni described the characteristic macroscopic and microscopic features of a breast lesion which he termed mammary hamartoma. ${ }^{1}$ These lesions are well circumscribed and both clinically and radiologically may resemble a fibroadenoma. Histologically, they are composed of acinar units, arranged in a lobular pattern within a hyalinised, fibrous stroma and containing variable amounts of fat in the interlobular regions. In addition to these typical features, this case also contained foci of ALH and LCIS with two foci of microinvasive lobular carcinoma. Although epithelial hyperplasia is reported as occurring only rarely, ${ }^{2}$ neoplastic lesions have not been documented in mammary hamartomas before as far as we know. ${ }^{34}$ It seems likely that its occurrence in this case, as in fibroadenomas, is coincidental and certainly not unexpected. Nevertheless, it emphasises the need for adequate sampling of macroscopically innocuous lesions as just over half the sections (57\%) contained lobular neoplasia and only two (14\%) contained microinvasive carcinoma.

We thank Miss M Garner for excellent secretarial assistance and Miss $\mathbf{P}$ Rowland for the photomicrographs.

1 Arrigoni MG, Dockerty MB, Judd ES. The identification and treatment of mammary hamartoma. Surg Gynecol Obstet 1971;133:577-82.

2 Fisher CJ, Hanby AM, Robinson L, Millis RR. Mammary hamartoma -a review of 35 cases. Histopathology 1992 20:99-106.

3 Oberman HA. Hamartoma and hamartoma variants of the breast. Semin Diagnost Pathol 1989;6:135-45.

4 Fechner RE. Fibroadenoma and related lesions. In: Page DL, Anderson TJ, eds. Diagnostic histopathology of the breast. Edinburgh: Churchill Livingstone, 1987:72-85
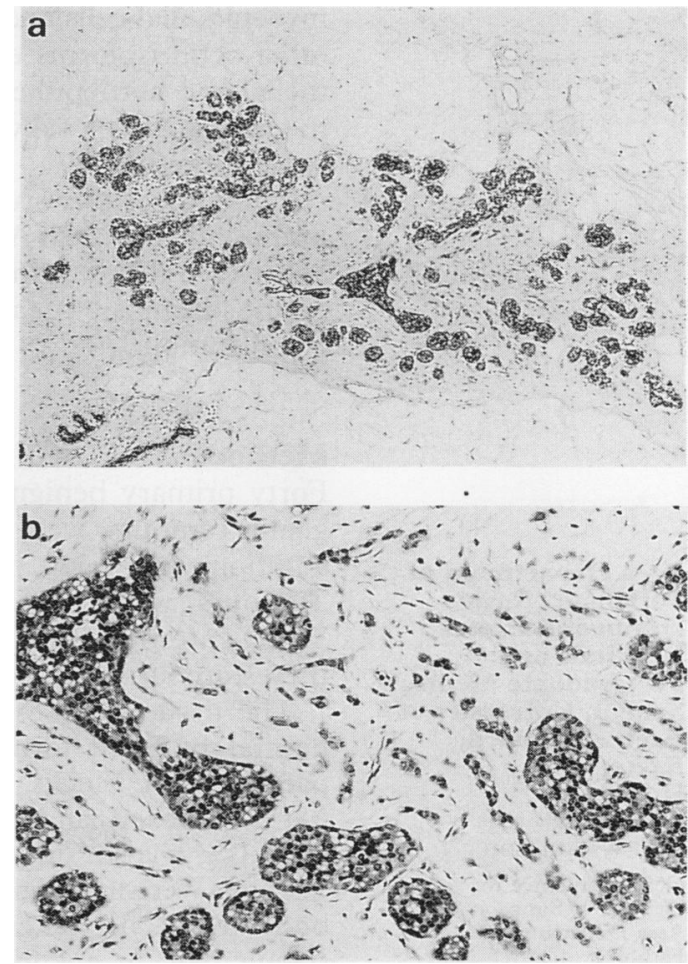

Figure 3 (A) Area of LCIS with invasive lobular carcinoma; $(B)$ higher magnification of invasive component. 